\title{
Nonoperative Management of Grade IV Liver Injury for Elderly Patient
}

\author{
Solvita Stabina*,*** Guntars Pupelis*,*** Reinis Laguns**, Aleksejs Kaminskis* \\ *Riga East Clinical University hospital Gailezers, General and Emergency Surgery Departament, Latvia \\ **Riga East Clinical University hospital Gailezers, Departament of Radiology, Latvia \\ *** Riga Stradins University, Latvia
}

\section{SUMMARY}

According to current conventional practice $80 \%$ to $90 \%$ of hepatic injuries can be safely managed without operation. (2) Previously conservative management of the hepatic injuries were recommended for hemodynamically stable patients who did not require blood transfusion and number of trauma centres strongly recommended conservative strategy in alert patient who are able to cooperate with physical examination. However recent experience shows that the key factor in determining whether non-operative management (NOM) can be safely used is hemodynamic stability (HD) of the patient.(5)

Key words: liver injury, hepatic trauma, operative management, non-operative management, blunt abdominal trauma, polytrauma

\section{AIM OF THE DEMONSTRATION}

Is to report the successful outcome in elderly patient with high grade liver injury who was managed according to non-operative treatment protocol.

\section{CASE REPORT}

71- year old female was delivered to the Emergency department (ED) four hours after accident with complaints about the chest and abdominal pain. Patient suffered in an auto-pedestrian accident and after accident felt dizziness and weakness however was able to go home and to call- an ambulance. At the time of admission she was haemodynamically stable maintaining blood pressure $130 / 80 \mathrm{mmHg}$ and heart rate 76 beats per minute. Chest X-ray revealed fracture of the IX rib. On focussed assessment with sonography for trauma(FAST) - liver contusion with hemoperitoneum were found.

CT showed liver laceration involving hepatic segments 7,8 (grade IV) and diffuse fluid collection in the peritoneal cavitywithout evidence of active extravasation.Elevated aspartate amino transferase (AST 465.41 U/L) and alanine aminotransferase (ALT 617.05 U/L) were the only abnormal blood tests. Haemoglobin was $12.30 \mathrm{~g} /$ $\mathrm{dL}$ and patient was haemodynamically stable during the primary assessment period. Patient was delivered to the Intensive care unit with the CT proved grade IV liver injury for NOM.Abdominal ultrasound and blood tests were repeated every 6 hours at the first day and once a day next 48 hours. This strategy was successful and patient was transferred to the surgical department. Overall hospital stay was 10 days. Patient was dischargedin a good conditionfor outpatient treatment.

\section{DISCUSSION}

Approximately $1 \%$ to $8 \%$ of patients who sustain blunt abdominal trauma have a liver injury. (4) Rapid deceleration in motor vehicle accidents produces shearing forces that cause different degrees of parenchymal tears. The hepatic lobes may be torn from each other, or the tears may involve the supporting ligaments, hepatic veins, and inferior vena cava. The most frequent site of hepatic injury is the posterior segment of the right lobe of the liver due to its size and proximity to the ribs and spine. Although less common, left lobe injuries are more often associated with retroperitoneal injuries (duodenum and pancreas) and transverse colon injuries. (1)(5)

NOM (6) is indicatedin all haemodynamically stabile patients when signs of peritonitis are absent on abdominal examination and surgeon is able to follow serial physical examinations, delineate hepatic injury and CT scan confirms absence of other intra-peritoneal injuries. Another important consideration is minimal transfusion requirements not exceeding 2 units of packed red blood cells (PRBCs). Complications of NOM such as biloma, biliary fistula, intra-abdominal abscess, hepatic abscess, haemobilia can be treated with percutaneous drainage, but missed hollow viscus injury, ongoing bleeding, liver necrosis and abdominal compartment syndrome often requires surgical treatment. 

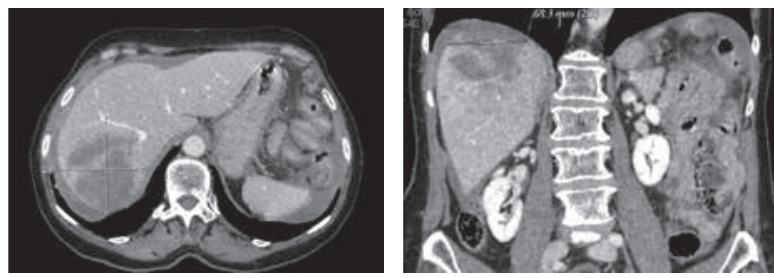

15.04.2014 Abdominal CT (at the admission)
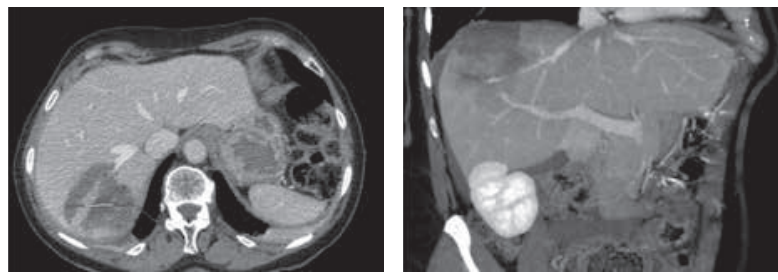

22.04.2014 Abdominal CT (7 days after trauma)

Conflict of interest: None

\section{REFERENCES}

1. Boone DC, Federle M, Billiar TR, et al Evolution of management of major hepatic trauma: Identification of patterns of injury // J Trauma, 1995; 39: 344 350 CrossRef

2. Carillo EH, Platz A, Richardson JD, et al: Nonoperative management of blunt hepatic trauma // Br J Surg, 1997; 85: 465 1 CrossRef

3. Jeffrey RB, Olcott EW: Imaging of blunt hepatic trauma // Radiol Clin North Am, 1991; 29: 1299 _ 1310

4. Matthes G, Stengel D, Seifert J, et al Blunt liver in polytrauma: Results from a cohort study with the regular use of whole - body helical computed tomography // World J Surg, 2003; 27: 1124 - 1130 CrossRef

5. Oschner MG: Factors of failure of nonoperative management of blunt liver and splenic injuries // World J Surg, 2001; 25: 1393

6. Alexander L. Eastman, David H. Rosenbaum and Erwin R. Thal // Parkland Trauma Handbook, The Third Edition 27, $210-22$

\section{Adress:}

Solvita Stabina

Talavas gatve $13-8$, Riga, Latvia

E-mail: solvita.stabina@inbox.lv 